Brazilian Journal

of Chemical

Engineering

\title{
SYNTHESIS OF SOLID CATALYST FROM DOLOMITE FOR BIODIESEL PRODUCTION USING PALM KERNEL OIL IN AN OPTIMIZATION PROCESS BY DEFINITIVE SCREENING DESIGN
}

\author{
Elijah O. Ajala ${ }^{1 *}$, Mary A. Ajala ${ }^{1}$, Temitope E. Odetoye ${ }^{1}$ and Anuoluwapo T. Okunlola ${ }^{1}$ \\ ${ }^{1}$ University of Ilorin, Department of Chemical Engineering, Ilorin, Nigeria. \\ E-mail: olawaleola01@yahoo.com - ORCID: 0000-0001-6856-3844; ORCID: 0000-0001-8714-7344
}

(Submitted: October 30, 2018 ; Revised: January 9, 2019 ; Accepted: January 10, 2019)

\begin{abstract}
A solid catalyst for biodiesel production was synthesized from dolomite by calcination at different temperatures of 800 and $900^{\circ} \mathrm{C}$ for $2 \mathrm{~h}$. The catalyst was characterized by scanning electron microscopy (SEM) and Brunauer Emmett Teller (BET). Its performance in the production of palm kernel biodiesel (PKB) using palm kernel oil in an optimization study was carried out by a definitive screening design. The varying process parameters for the optimization were methanol:oil molar ratio, reaction temperature, catalyst quantity, reaction time and dolomite calcination temperature. Tendency and extent of the catalyst reusability were also studied. The catalysts were found to contain calcium and magnesium oxides with morphological structures of: surface areas 507 and $560 \mathrm{~m}^{2} / \mathrm{g}$, pore volumes 0.180 and $0.199 \mathrm{~cm}^{3} / \mathrm{g}$, and pore sizes 27.07 and $31.48 \hat{\mathrm{A}}$ for Dolomite Catalyst Calcined (DCC) at $800^{\circ} \mathrm{C}(\mathrm{DCC} 800)$ and $\mathrm{DCC}$ at $900^{\circ} \mathrm{C}$ (DCC900), respectively. The optimal parameters of methanol:oil molar ratio $12: 1$, temperature $65^{\circ} \mathrm{C}$, catalyst quantity $8 \%(\mathrm{w} / \mathrm{w})$, time $4 \mathrm{~h}$ and DCC800 gave an optimum yield of $98.69 \%$ biodiesel. The catalyst was reused for the $8^{\text {th }}$ cycle after which the \%yield of PKB decreased by $<4 \%$. It can be concluded that the dolomite catalyst has a great activity and potential as a viable catalyst for quality biodiesel production.

Keywords: Fatty acid methyl esters; Definitive screening design; Palm kernel oil; Dolomite; Catalyst.
\end{abstract}

\section{INTRODUCTION}

Today's demand for a sustainable and alternative energy source to fossil fuel has increased the attention of various researchers to the production of biodiesel for diesel engines. As biodiesel is biodegradable, non-toxic, renewable and environmentally benign (Jindapon et al., 2016; Ngamcharussrivichai et al., 2007). Biodiesel is generally synthesized through the transesterification reaction of triglycerides obtained from either vegetable oils or animal fats with a short chain alcohol such as methanol or ethanol, in the presence of a catalyst (Korkut and Bayramoglu, 2016; Niu et al., 2014). The catalyst can either be homogeneous or heterogeneous to form mono-alkyl esters from the reaction, a long chain fatty acid ester known as biodiesel, and glycerol as a byproduct (Correia et al., 2014).

Heterogeneous catalysts have been reported as preferred to the homogeneous catalysts because of several benefits identified in the literature (Jindapon et al., 2016; Roschat et al., 2016). The heterogeneous catalysts, that include calcium and magnesium oxides, are low-cost resources for biodiesel synthesis, as this would reduce the cost of biodiesel production and simultaneously produce the catalysts with costeffectiveness (Muthu and Viruthagiri, 2015). There are several natural calcium sources such as in waste food materials and in the earth's crust. Some of this calcium has been employed as a solid catalyst for biodiesel

\footnotetext{
* Corresponding author: E. O. Ajala - E-mail: olawaleola01@yahoo.com
} 
production (Jazie et al., 2013a; Mohan, 2015). The presence of calcium oxide in heterogeneous catalysts has been reported to provide high tolerance capacity for moisture and free fatty acid in the reactants and non-corrosiveness of equipment and non-toxic nature (Mohan, 2015). Calcium oxide $(\mathrm{CaO})$ as a catalyst material for biodiesel production provides additional advantages such as low cost, and high catalytic activity. The $\mathrm{CaO}$ can be synthesized from a number of natural resources such as waste obtuse horn, waste coral fragment, hydrated lime and chicken bones (Roschat et al., 2016) as well as natural rocks such as calcite and dolomite (Muthu and Viruthagiri, 2015). Natural calcium carbonate $\left(\mathrm{CaCO}_{3}\right)$ rocks serve as cheap raw material for the catalyst, though it has low activity and requires high reaction temperature to attain above $95 \%$ conversion of triglycerides to biodiesel (Ngamcharussrivichai et al., 2007). Several efforts to synthesize the catalyst to achieve these have been made, which eventually turned out to be quite costly. But by considering factors such as the cost and product quality, cheaper sources such as dolomite can be explored (Sulaiman et al., 2017)

Dolomite $\left(\mathrm{CaMg}\left(\mathrm{CO}_{3}\right)_{2}\right)$ is a natural mineral that consists mainly of calcium and magnesium carbonate with other compounds present in small concentrations. The dolomite is present in abundance in many parts of the world as a common continental, marine sedimentary and metamorphic rock (Correia et al., 2015). The rock can be used in animal feed and, in Nigeria, it is used in fertilizer production and construction work. Like other natural sources of $\mathrm{CaCO}_{3}$, the thermal decomposition of dolomite into $\mathrm{CaO}$ and $\mathrm{MgO}$ provides its active phases which make it suitable as a catalyst in the alcoholysis of vegetable oil or animal fats to fatty acid methyl esters (FAME) (Monteiro et al., 2009; Shajaratun Nur et al., 2014).

A great number of vegetable oils (soybean, hazelnut, and castor oil) and animal fats (sheep fat, fish oil, and chicken fat) have been utilized for biodiesel production as renewable resources that were expected to decrease the cost of production and lower the environmental pollution (Gorji, 2015). Biodiesel synthesized from vegetable oil is attracting improved attention as a potential alternative to petrol-based diesel fuel due to the physicochemical characteristics and abundant availability in a region. Other factors that shifted the attention to using vegetable oil ahead of animal fats for biodiesel production are identified as adaptability to growing conditions in a locality, highly rich in oil content, and low free fatty acid composition. Others include ease of cultivation using existing farm practices, reduced agricultural inputs, a consistent pattern of the growing season, uniform rates of maturation for seed, availability of a market for byproducts, rotational adaptability with commodity crops and compatibility with fallow lands (Jazie et al., 2013a). Palm kernel oil (PKO) meet all or most of these criteria, hence holds the greatest promise as a suitable raw material for biodiesel production.

The PKO is obtained from a palm tree called Elaeis guineensis, which originated from the tropical rainforest region of West Africa (Ezeoha et al., 2012). The PKO has been used for several purposes as well as for biodiesel production (Alamu et al., 2008). Alamu et al. (2008) reported its use for biodiesel with an average yield of $98.80 \%$ when a homogeneous catalyst was used. Aladetuyi et al. (2014) also utilized PKO for biodiesel production in the presence of a heterogeneous catalyst (Cocoa pod ash) and obtained an average yield of $94 \%$. From the aforementioned earlier works on PKO conversion to biodiesel, the use of dolomite as a source of the catalyst was not investigated. However, Ngamcharussrivichai et al. (2007) reported the modification of dolomite for biodiesel production using PKO, but the dolomite was from Thailand and modified before used. Hence, biodiesel production using pure dolomite had not been extensively studied and there was no report on the use of Nigerian dolomite as a solid catalyst for biodiesel production (Korkut and Bayramoglu, 2016). Moreover, optimization of the dolomitic catalytic process of PKO for biodiesel synthesis had not been investigated.

The optimization process of biodiesel production is through the application of experimental design tools to optimize the process parameters that could improve the biodiesel yield. There are several of these experimental design tools reported in the literature, particularly the traditional experimental designs (Ferdous et al., 2013; Gupta et al., 2016; Singh et al., 2006; Xuan et al., 2011). However, there is a paucity of information on the use of experimental design tools such as definitive screening design (DSD) and Mixture design for biodiesel production. The DSD can reduce the number of experimental runs, modeling power, and statistical error, with a mid-sizeable number of process factors (Jones and Nachtsheim, 2013). The DSD is preferred over the traditional experimental designs due to numerous advantages, as highlighted in the literature (Donnelly, 2016; Marcel, 2015).

In this research, a highly active catalyst from Nigerian dolomite rock was synthesized and tested for its effectiveness. The effects of catalyst calcination temperatures of 800 and $900^{\circ} \mathrm{C}$ on the catalyst characteristics were studied. The chemical compositions, morphological structure and surface area, pore volume and size of the catalyst were determined using various equipment and analyses. The effectiveness of the catalyst was tested in the optimization of process parameters for the transesterification of PKO into FAME using DSD. The parameters investigated were methanol:oil molar ratio, 
temperature, catalyst quantity, reaction time and CCT. The possibility and extent of the catalyst reusability were also investigated. The quality of the biodiesel was ascertained after purification by determining its physicochemical properties using the ASTM methods and the FAME profile by gas chromatography (GC).

\section{MATERIALS AND METHODS}

\section{Materials and Reagents}

Equipment used includes an Armfield batch reactor (CEXC-A, 036223-003), MTN Medium Speed Trapezum Mill (Md 100, Pom37 Serial Number 2011100), Vacuum furnace (CWF1300) produced by Carbolite, and Atomic Absorption Spectrophotometer (AAS)/Flame Photometer (FP), Buck Scientific Accusys 211 model. Fourier transforms infrared spectroscopy (FT-IR), model Shimadzu (8400S) spectrometer, Scanning Electron Microscopy (SEM) with Energy-dispersive X-ray spectrometry (EDX), model FEI ESEM Quanta 200 and Brunauer-EmmettTeller (BET), Nova Quantachrome version 11.03 were also among the equipment employed for the study. Gas chromatography (GC), Agilent 7890A model, equipped with triple axis detector and autosampler injector was used for FAME analysis.

The PKO was obtained from a local market in Obaagun, Osun State, Nigeria. Dolomite of size 22.5 $\mathrm{cm}$ was collected at Oke Oyan, Kwara State, Nigeria. Methanol of analytical grade from Sigma Aldrich and Aqua Regia solution were used for the research.

\section{Dolomite Catalyst Preparation}

Dolomite was pulverized to a fine powder using the Speed Trapezum Mill and stored in an air-tight polythene container/bag. The dolomite was weighed into crucibles and calcined at 800 and $900^{\circ} \mathrm{C}$ for 2 $\mathrm{h}$ using a cumulative heating rate of $30^{\circ} \mathrm{C} / \mathrm{min}$ in a Vacuum furnace (CWF1300). The dolomite was heated to decompose the organic matter in it and also to convert $\mathrm{CaMg}\left(\mathrm{CO}_{3}\right)_{2}$ or $\mathrm{CaCO}_{3}$ to $\mathrm{MgO}$ or/ and $\mathrm{CaO}$ (Correia et al., 2014). The calcined samples were cooled and transferred into airtight polythene containers prior to storage in a desiccator to prevent absorption of moisture.

\section{Dolomitic Catalyst Characterization}

The natural dolomite and the dolomitic catalysts of 800 and $900^{\circ} \mathrm{C}$ (DCC800 and DCC900) were digested using $12 \mathrm{ml}$ Aqua Regia solution $\left(\mathrm{HNO}_{3} 67 \%\right.$ : $\mathrm{HCl}$ $37 \%=3: 1)$. The digested solution was stirred for 20 min using a magnetic stirrer and thereafter filtered through a Whatman ${ }^{\circledR}$ No 42-filter paper into a 50 $\mathrm{ml}$ polypropylene vial and diluted to $25 \mathrm{ml}$ with the extracting solution.

The digested samples were characterized using various analytical equipment. AAS/FP was used to determine the concentration of the ions at wavenumber corresponding to each element as indicated by the manufacturer. The concentration of calcium $(\mathrm{Ca})$, magnesium $(\mathrm{Mg})$, iron $(\mathrm{Fe})$, zinc $(\mathrm{Zn})$ and copper $(\mathrm{Cu})$ were measured as well as the concentration of sodium (Na) and potassium (K). The FT-IR was employed to observe the infrared spectra of the samples by pelletizing it with potassium bromide $(\mathrm{KBr})$. The spectrum was obtained from the accumulation of 32 scans in the range of wavenumbers $450-4000 \mathrm{~cm}^{-1}$ with a resolution of $4 \mathrm{~cm}^{-1}$. The morphological structure of both the natural dolomite and dolomitic catalysts were determined using the Scanning Electron Microscope and Energy Dispersive Spectroscopy (SEM-EDS). The specific surface area, pore volume and pore size distribution of the DCC 800 and DCC900 were measured using the BET.

\section{Experimental Design and Data Analysis by Definitive Screening Design (DSD)}

The experimental design for the process parameters was done using the DSD of SAS JMP Statistical Discovery version 11.0. This was with the aim to optimize the process parameters for optimum yield of biodiesel using dolomitic catalyst on PKO. The design considered five factors at three levels of minimum, center and maximum with a total number of 18 experimental runs as shown in Table 1. The relationship between the \%Yield of Biodiesel (Y), which is the response and the process parameters: methanol:oil molar ratio (MeOH:oil mole ratio), temperature, catalyst quantity, reaction time and dolomite calcination temperature as $\mathrm{X}_{1} \mathrm{X}_{2} \mathrm{X}_{3} \mathrm{X}_{4}$ and $\mathrm{X}_{5}$, respectively was proposed as a model of Eq. 1 .

$$
\begin{aligned}
\mathrm{Y} & =\mathrm{b}_{0}+\mathrm{b}_{1} \mathrm{X}_{1}+\mathrm{b}_{2} \mathrm{X}_{2}+\ldots+ \\
& +\mathrm{b}_{\mathrm{n}} \mathrm{X}_{\mathrm{n}}+\sum \mathrm{b}_{\mathrm{ik}} \mathrm{X}_{\mathrm{i}} \mathrm{X}_{\mathrm{k}}+\sum \mathrm{b}_{\mathrm{ii}} \mathrm{X}_{\mathrm{i}}^{2}
\end{aligned}
$$

where; $b_{o}, b_{1}, b_{2} \ldots b_{n}$ are the constants.

The model equation (Eq. 1) was analyzed using multiple regression to evaluate the response by analyzing the linear and interaction effects of the process parameters. The significance of each process parameter as coefficients and those of their interactions were tested based on the $\mathrm{H}_{0}$ hypothesis, which says $\mathrm{H}_{0}$ assumes a given coefficient is not significant. The significant effect of each of the process parameter was analyzed using its $p$-value and was considered significant when $p<0.05$.

\section{Dolomitic Catalyst Test through Transesterification Reaction of PKO}

The transesterification reaction was carried out using the batch reactor (Figure 1) with a temperaturecontroller and a stirrer operating at $100 \mathrm{rpm}$. The process parameters varied in the reaction were methanol-to-oil molar ratio, catalyst quantity, reaction 
Table 1. Factors and Levels that Affect the \%Yield of Biodiesel by a Definitive Screening Design.

\begin{tabular}{|c|c|c|c|c|c|}
\hline \multicolumn{2}{|l|}{ Response Name } & \multicolumn{2}{|c|}{ Goal } & Lower Limit & Upper Limit \\
\hline \multicolumn{2}{|l|}{$\%$ Yield of Biodiesel } & \multicolumn{2}{|c|}{ Maximize } & - & - \\
\hline Factors/Name & Codes & Roles & Coded range & & \\
\hline MeOH:Oil Molar Ratio (w/w) & $\mathrm{X}_{1}$ & Continuous & $-1,0,1$ & 6 & 12 \\
\hline Temperature $\left({ }^{\circ} \mathrm{C}\right)$ & $\mathrm{X}_{2}$ & Continuous & $-1,0,1$ & 55 & 65 \\
\hline Catalyst Quantity (w/w) & $\mathrm{X}_{3}$ & Continuous & $-1,0,1$ & 4 & 8 \\
\hline Reaction Time (h) & $\mathrm{X}_{4}$ & Continuous & $-1,0,1$ & 2 & 4 \\
\hline $\operatorname{DCT}\left({ }^{\circ} \mathrm{C}\right)$ & $\mathrm{X}_{5}$ & Categorical & 0,1 & 800 & 900 \\
\hline
\end{tabular}

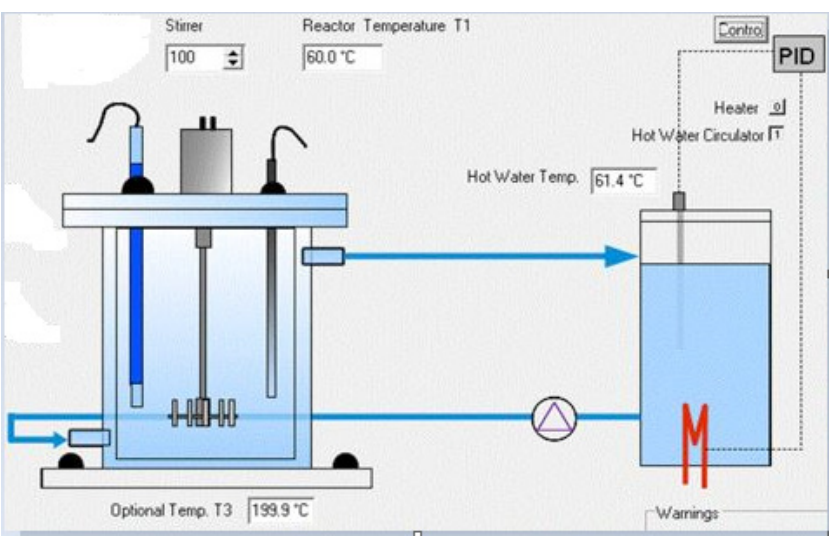

Figure 1. Reactor set up.

time, reaction temperature and the dolomitic catalyst calcination temperature (DCC800 and DCC900) as a categorical factor (Table 1).

Three hundred grams $(300 \mathrm{~g})$ of PKO and the required quantity of catalyst $(4,6$ or $8 \%, w / w$ of $\mathrm{PKO})$ with $\mathrm{MeOH}$ :oil molar ratio $(6,9$, or $12 \mathrm{w} / \mathrm{w})$ were measured into the reactor. The reactor temperature was adjusted $\left(55,60\right.$ or $\left.65^{\circ} \mathrm{C}\right)$ for a reaction time of 2,3 or $4 \mathrm{~h}$ with continuous agitation. At the expiration of the reaction time, the catalyst was separated from the mixture containing the biodiesel by centrifuging at 1000 $\mathrm{x} g$ for $5 \mathrm{~min}$. The supernatant containing FAME was transferred to a separating funnel to remove glycerol. The FAME was charged into a vacuum rotary evaporator to eliminate the excess methanol left in the product. The product was further purified by using anhydrous sodium sulfate to remove traces of water and the quantity of biodiesel was determined using Eq. 2.

$\%$ Yield of biodiesel $=\frac{\text { Amount of produced biodiesel }}{\text { Amount of oil used }} \times 100$

The reusability of the dolomitic catalyst was tested using a certain quantity of the catalyst repeatedly for nine cycles in the transesterification reaction. The catalyst was separated from the previous reaction mixture by centrifugation, washed with n-hexane, and oven dried at $60^{\circ} \mathrm{C}$ before each reuse.

\section{Physicochemical Characterization and GC Analysis of the PKB}

The physicochemical properties of the PKB synthesized through dolomitic catalyst were determined using the standard methods of ASTM. The results obtained were compared with the ASTM standards for biodiesel.

The FAME profile of the biodiesel was carried out using the GC. The sample bottle was filled with the biodiesel and put on the sample tray for the analysis. The sample was injected into the GC at split mode (50:1) through a $30 \mathrm{~m}$ polar Agilent 190925-433 capillary column. The chromatograms obtained were compared with those of the standard chromatograms from the NIST library (NIST 11).

\section{RESULTS AND DISCUSSION}

\section{Dolomitic Catalyst Characterization}

Table 2 shows the elemental composition of the natural dolomite, DCC 800 , and DCC900, which were determined using the AAS/FP. The elemental content (\%) of the samples shows that the natural dolomite contains calcium $(\mathrm{Ca}), 54.29$, magnesium $(\mathrm{Mg}), 39.71$, sodium $(\mathrm{Na}), 0.6$, potassium $(\mathrm{K}), 0.07$, iron $(\mathrm{Fe}), 0.13$, zinc $(\mathrm{Zn}), 0.034$ and copper $(\mathrm{Cu}), 0.00143$. The DCC 800 and DCC 900 show compositions of $\mathrm{Ca} / \mathrm{Mg} / \mathrm{Na} / \mathrm{K} / \mathrm{Fe}$ of 56.12/42.09/0.8/0.1/0.23 and55.21/42.02/1.02/0.9/0.47, respectively, while other elements are present in traces. The calcination process of the dolomite shows maginal increase in the concentration of $\mathrm{Ca}, \mathrm{Na}, \mathrm{K}$ and $\mathrm{Fe}$ in the catalysts (DCC800 and DCC900). This is due to the decomposition of carbonates and elimination of volatile compound that might be present in the dolomite (Almerindoa et al., 2011). The catalysts are suitable for the transesterification of triglycerides as they contain essential ingredients $(\mathrm{Ca}, \mathrm{Mg}, \mathrm{Na}$ and $\mathrm{K}$ ) to produce biodiesel.

The FT IR spectra of natural dolomite, DCC 800 and DCC900 are shown in Fig. 2. There is a weak

Table 2. Elemental Composition of Natural Dolomite, DCC 800 and DCC900 using AAS/PF.

\begin{tabular}{cccc}
\hline Elements (\%) & $\begin{array}{c}\text { Natural } \\
\text { Dolomite }\end{array}$ & DCC800 & DCC900 \\
\hline Calcium $(\mathrm{Ca})$ & 54.29 & 56.12 & 55.21 \\
Magnesium $(\mathrm{Mg})$ & 39.71 & 42.09 & 42.02 \\
Sodium $(\mathrm{Na})$ & 0.6 & 0.8 & 1.02 \\
Potassium $(\mathrm{K})$ & 0.07 & 0.1 & 0.9 \\
Iron $(\mathrm{Fe})$ & 0.13 & 0.23 & 0.47 \\
Zinc $(\mathrm{Zn})$ & 0.034 & 0.06 & Trace \\
Copper $(\mathrm{Cu})$ & 0.00143 & Trace & Trace \\
\hline
\end{tabular}




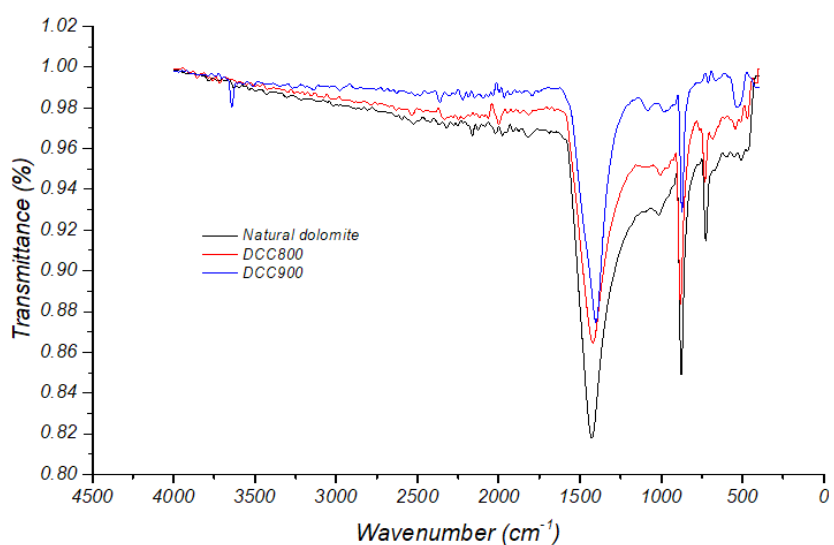

Figure 2. FTIR Spectra of Natural Dolomite, DCC800 and DCC 900 .

absorption peak observed for natural dolomite at about $3600 \mathrm{~cm}^{-1}$. The peak indicates the formation of basic $\mathrm{OH}$ groups associated with adsorbed water which can attach to the calcium and/or magnessium atoms (Margaretha et al., 2012). The DCC 800 and DCC900 infrared spectra show no observable absorption peak at $3600 \mathrm{~cm}^{-1}$ region implying the absence of the $\mathrm{OH}$ group. The disappearance of this band is due to the thermal treatment of the samples. Weak bands were noticed at 2000 and $1950 \mathrm{~cm}^{-1}$ for the three samples. Other peaks present are 1400, 1000, 880, 740 and 500 $\mathrm{cm}^{-1}$ for the three samples which are similar to the picks observed by Ji et al. (2009) for dolomites. The peaks at 1400 and $880 \mathrm{~cm}^{-1}$ characterized $\mathrm{C}-\mathrm{O}$ stretching and bending modes of $\mathrm{CaCO}_{3}$ and/or $\mathrm{MgCO}_{3}$ in which they decomposed into $\mathrm{CaO}$ and/or $\mathrm{MgO}$ and $\mathrm{CO}_{2}$ during calcination (Margaretha et al., 2012). The bands confirms the presence of carbonates $\left(\mathrm{CO}_{3}^{2-}\right)$ in the dolomite structure (Ji et al., 2009). Furthermore, the spectra also indicate plane bending vibrational bands which show the presence of carbonates which means that the dolomite contains carbonate group (Hariharan et al., 2014). Except for the presence of the $\mathrm{OH}$ functional group in the natural dolomite, all the three samples show similar infrared spectra. This suggests that the thermal treatment of natural dolomite only affects the $\mathrm{OH}$ functional groups.

The morphologies and composition of the three samples as shown in Figs. 3(a-c) and Table 3, respectively, were determined using the SEM-EDS. From the SEM images, it is observed that the natural sample (Fig. 3a) shows a high degree of agglomeration with a smooth surface but no visible pores. Fig. $3 b$ is the SEM of the DCC 800 and shows an arrangement of solid particles in a crystalline matrix with a rough surface (Almerindoa et al., 2011). The figure shows improved surface area with visible pores compared to the natural dolomite. Fig. 3c is the SEM of DCC900, which shows irregular shape with some of them bonded to form a large surface area. The figure reveals
A.
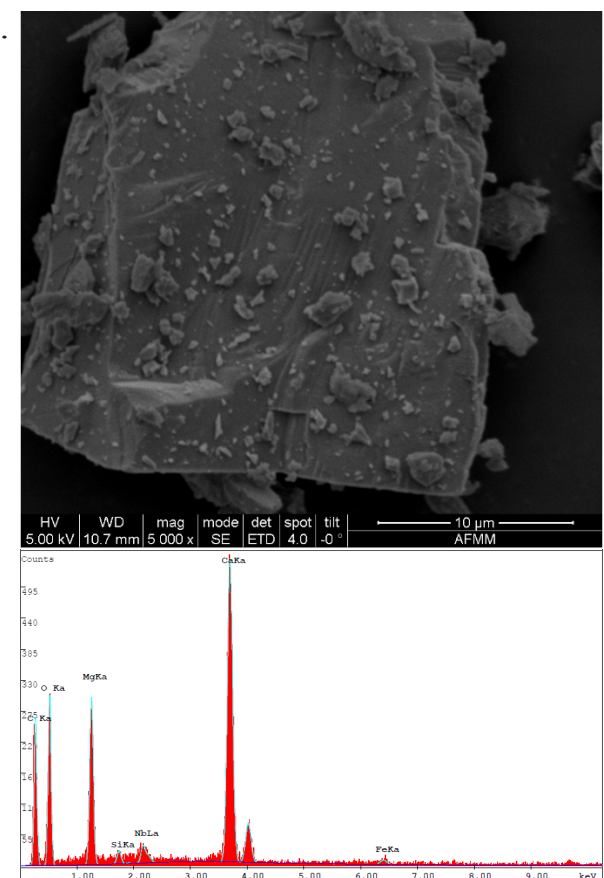

B.
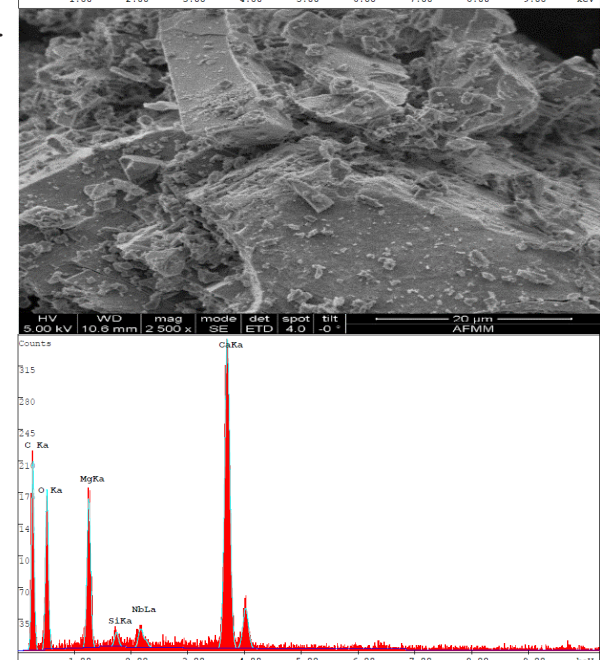

C.
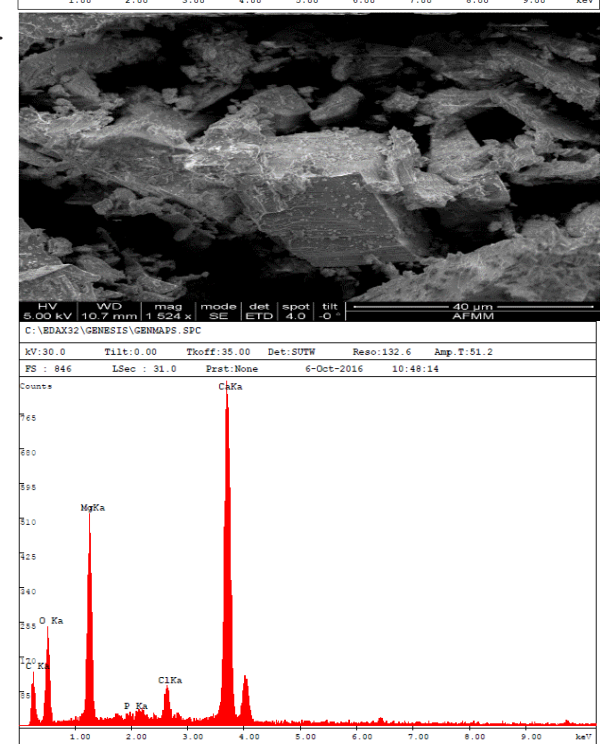

Figure 3. SEM and EDAX Images of (a) Natural Dolomite (b) DCC800 (c) DCC900. 
Table 3. EDS Quantitative Analysis.

\begin{tabular}{ccccccc}
\hline \multirow{2}{*}{ Elements (\%) } & \multicolumn{2}{c}{ Natural Dolomite } & \multicolumn{2}{c}{ DCC800 } & \multicolumn{2}{c}{ DCC900 } \\
\cline { 2 - 7 } & Wt \% & At \% & Wt \% & At\% & Wt \% & At \% \\
\hline Calcium (Ca) & 10.48 & 3.99 & 10.84 & 4.24 & 19.20 & 8.54 \\
Magnesium & 7.34 & 4.61 & 8.88 & 5.72 & 16.27 & 11.94 \\
Carbon (C) & 40.12 & 52.32 & 43.44 & 56.06 & 26.90 & 39.94 \\
Oxygen (O) & 37.92 & 37.12 & 35.37 & 33.75 & 34.47 & 38.43 \\
Others & 4.14 & 1.96 & 1.46 & 0.23 & 3.16 & 1.15 \\
\hline
\end{tabular}

large pore volume and cavities, which are due to the elimination of volatile materials by higher calcination temperature. Figs $3 \mathrm{~b}$ and $3 \mathrm{c}$ are similar to those reported by Santos et al. (2014) and show significant differences compared to Fig. 3a. This can be attributed to the decomposition of the carbonate groups by giving off $\mathrm{CO}_{2}$ with the formation of $\mathrm{CaO}$ and $\mathrm{MgO}$ phases.

The quantitative elemental analysis by EDS as shown by the graphs in Fig 3 and analyzed in Table 3 revealed the atomic weight of the samples. The natural dolomite shows the percentage composition (\%) of calcium $(\mathrm{Ca})$ 10.48, magnesium $(\mathrm{Mg}) 7.34$, carbon (C) 40.12, oxygen (O) 37.92 and others 4.14. The DCC 800 was composed of Ca 10.84, Mg 8.88, C 43.44, O 35.37 and others. The DCC900 composed of Ca 19.20, Mg 16.27, C 26.90, O 34.47 and others 3.16. The EDS further confirmed the presence of essential elements $(\mathrm{Mg}$ and $\mathrm{Ca})$ in appreciable quantity for biodiesel production in the catalysts. The result revealed that DCC900 gave a better quantity of the essential elements than DCC800, an indication that the thermal decomposition at higher temperature can decompose metal carbonate to $\mathrm{CaO}$ and $\mathrm{MgO}$ phase formation (Santos et al., 2014). Hence, dolomite is a good raw material for catalyst synthesis for biodiesel production.

The textural properties of the dolomite catalysts synthesized at different calcination temperatures were determined by BET measurement, while the distribution of pores volume and size was calculated by the DR method (Table 4). The results showed that the surface area, pore volume and pore size of the DCC 800 were $507 \mathrm{~m}^{2} / \mathrm{g}, 0.180 \mathrm{~cm}^{3} / \mathrm{g}$, and $27.07 \hat{\mathrm{A}}$, whereas the DCC900 catalyst exhibited an increase in the surface area, pore volume, and pore size to 560 $\mathrm{m}^{2} / \mathrm{g}, 0.199 \mathrm{~cm}^{3} / \mathrm{g}$ and $31.48 \hat{\mathrm{A}}$, respectively. These results implied the formation of a new phase by the increase in the calcination temperature. Therefore, calcination at a higher temperature may be a necessary step to convert the metal carbonate salts to active metal oxide catalyst for the transesterification reaction. This

Table 4. Surface Area Profile of Dolomitic Catalysts.

\begin{tabular}{cccc}
\hline $\begin{array}{c}\text { Dolomitic } \\
\text { catalysts }\end{array}$ & $\begin{array}{c}\text { BET } \\
\text { Area } \\
\left(\mathbf{m}^{\mathbf{2}} / \mathbf{g}\right)\end{array}$ & $\begin{array}{c}\text { Pore } \\
\text { volume } \\
\left(\mathbf{c m}^{3} / \mathbf{g}\right)\end{array}$ & $\begin{array}{c}\text { Pore } \\
\text { diameter } \\
(\hat{\mathbf{A}})\end{array}$ \\
\hline DCC800 & 507 & 0.180 & 27.07 \\
DCC900 & 560 & 0.199 & 31.48 \\
\hline
\end{tabular}

is to remove the strong bonding of carbonate from the catalyst surface (Jazie et al., 2013b; Lee et al., 2014).

\section{Optimization of the Process Parameters by the DSD for \% Yield of Biodiesel}

Statistical analysis by analysis of variance (ANOVA)

Evaluation of the adequacy of the fitted model was carried out using ANOVA to determine the significance of the process parameters as they affect the \%yield of biodiesel from PKO. The results of \%yield of biodiesel obtained for each set of an experimental matrix of parametric conditions are shown in Table 5. The ANOVA results are shown in Table 6, which comprised Fischer's statistical test ( $F$ value), probabilities of the model and those of each parameter ( $p$-value), and coefficient of variance $\left(R^{2}\right)$. The $F$ value of 30.145 obtained is large enough to show the significance of the model with the $p$-value of $<.0001$. Therefore, the model should be effective in the optimization of the process parameter for the \%yield of biodiesel from PKO using the synthesized catalyst from Nigerian dolomite. Furthermore, the ANOVA results show that the $\mathrm{MeOH}$ :oil mole ratio $(\mathrm{w} / \mathrm{w})$ and temperature are the most significant parameters with F-value of 107.240 and 19.05 respectively and a $p$-value of $<0.0001$ and 0.0009 , respectively. The reaction time and catalyst calcination temperature are also significant with a $p$-value of 0.0046 and 0.0016 respectively. The $\mathrm{R}^{2}$ of the model obtained is 0.9263 ( $\mathrm{R}^{2}$ Adjusted of 0.8955$)$, an indication that the model fits perfectly with the experimental data. It implies that $92.63 \%$ of the variability in the process parameters can be explained. Therefore, the model is strong enough for the optimization of this study. The $\mathrm{R}^{2}$ shows the perfectness of the model as it fits the experimental data since the value is close to unity, signifying that the experimental data linearly fits in the model equation. The $\mathrm{R}^{2}$ and the $\mathrm{R}^{2}$ Adjusted are reasonably in agreement with each other with a difference of 0.0308 , which is lower than the maximum allowable difference of 0.2 (Dhawane et al., 2016). The regression analysis was also carried out to determine which of the process parameters is most influential on the \%yield of biodiesel. The model equation (Eq. 1) was solved to obtained coefficients for each of the parameters with a $95 \%$ confidence level as shown mathematically in Eq. 3, in term of a coded factor. From the Eq. 3, it was noticed that the interactions and quadratic terms of the 
Table 5. Result of Experimental Matrix by the DSD for Transesterification of PKO to Biodiesel.

\begin{tabular}{ccccccc}
\hline $\begin{array}{c}\text { Exp. } \\
\text { Runs }\end{array}$ & $\begin{array}{c}\text { MeOH:oil Mole } \\
\text { Ratio } \mathbf{( w / w )}\end{array}$ & $\begin{array}{c}\text { Temperature } \\
\mathbf{(} \mathbf{C})\end{array}$ & $\begin{array}{c}\text { Catalyst Quantity } \\
(\mathbf{\%}, \mathbf{w} / \mathbf{w})\end{array}$ & $\begin{array}{c}\text { Reaction } \\
\text { Time }(\mathbf{h})\end{array}$ & $\begin{array}{c}\text { Catalyst Calcined } \\
\text { Temperature }\left({ }^{\mathbf{0}} \mathbf{C}\right)\end{array}$ & $\begin{array}{c}\text { \%Yield of } \\
\text { Biodiesel }\end{array}$ \\
\hline 1 & 6 & 65 & 6 & 2 & 800 & 93.71 \\
2 & 12 & 65 & 4 & 2 & 900 & 95.52 \\
3 & 6 & 55 & 8 & 2 & 900 & 90.23 \\
4 & 12 & 55 & 6 & 4 & 900 & 94.06 \\
5 & 9 & 55 & 4 & 2 & 800 & 91.8 \\
6 & 9 & 60 & 6 & 3 & 800 & 94.36 \\
7 & 9 & 60 & 6 & 3 & 900 & 93.29 \\
8 & 6 & 55 & 8 & 4 & 800 & 92.96 \\
9 & 9 & 65 & 8 & 4 & 900 & 95.41 \\
10 & 12 & 65 & 4 & 4 & 800 & 98.02 \\
11 & 6 & 55 & 4 & 4 & 800 & 92.54 \\
12 & 6 & 65 & 4 & 4 & 900 & 91.95 \\
13 & 12 & 65 & 8 & 2 & 900 & 95.41 \\
14 & 6 & 60 & 4 & 2 & 900 & 89.47 \\
15 & 12 & 55 & 8 & 2 & 800 & 95.49 \\
16 & 12 & 55 & 4 & 3 & 900 & 95.56 \\
17 & 12 & 60 & 8 & 4 & 800 & 97.97 \\
18 & 6 & 65 & 8 & 3 & 800 & 93.45 \\
\hline
\end{tabular}

Table 6. Statistical Analysis by ANOVA for Significance Level of Process Parameters.

\begin{tabular}{|c|c|c|c|c|c|c|}
\hline Source & $\begin{array}{c}\text { Sum } \\
\text { of Squares }\end{array}$ & Df & $\begin{array}{c}\text { Standard } \\
\text { Error }\end{array}$ & t Ratio & F Ratio & Prob $>$ ItI \\
\hline Model & 84.141 & 5 & 0.176 & 533.51 & 30.145 & $<.0001$ \\
\hline MeOH: Oil Mole Ratio (w/w) & 59.866 & 1 & 0.201 & 10.36 & 107.240 & $<.0001$ \\
\hline Temperature $\left({ }^{\circ} \mathrm{C}\right)$ & 10.635 & 1 & 0.201 & 4.36 & 19.050 & 0.0009 \\
\hline Catalyst Quantity $(\%, w / w)$ & 1.477 & 1 & 0.201 & 1.63 & 2.645 & $0.1298 *$ \\
\hline Reaction Time (h) & 6.753 & 1 & 0.201 & 3.48 & 12.097 & 0.0046 \\
\hline $\mathrm{CCT}\left(800^{\circ} \mathrm{C}\right)$ & 9.166 & 1 & 0.182 & 4.05 & 16.419 & 0.0016 \\
\hline Residual & 6.699 & 12 & & & & \\
\hline $\mathbf{R}^{2}$ & $\mathbf{R}^{2}$ Adj & \multicolumn{2}{|c|}{$\begin{array}{l}\text { Root Mean } \\
\text { Square Error }\end{array}$} & $\begin{array}{c}\text { Mean } \\
\text { of Response }\end{array}$ & \multicolumn{2}{|c|}{ Observations (or Sum Wgts) } \\
\hline 0.9263 & 0.8955 & \multicolumn{2}{|c|}{0.7472} & 93.96 & \multicolumn{2}{|c|}{18} \\
\hline
\end{tabular}

process conditions were the very less impact on the $\%$ yield of PKB. The equation is to predict the outcome of the \%yield of biodiesel at any given level of each process parameter. The equation can also be used to determine the relative impact of the parameters by comparing their coefficients.

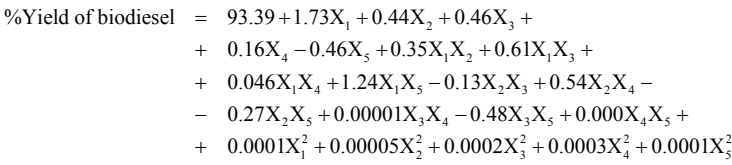

Fig. 4 shows the Pareto distribution chart to show the individual effect of process parameters on the $\%$ yield of biodiesel. The figure further confirms that the $\mathrm{MeOH}$ :oil mole ratio $(\mathrm{w} / \mathrm{w})$ and temperature are the most significant parameters with contributing effect of $\log$ worth of 6.611 and 3.036 respectively, followed by catalyst calcination temperature (2.795) and reaction time (2.341) in that order, while catalyst quantity $(0.887)$ is the least. These values were used to judge the adequacy of the model and the significance of each parameter. The fit of the model was tested via the residual distribution graph as shown in Fig. 5. It was observed that the residual distribution results did not show the typical pattern expected of the predicted results for the \%yield of biodiesel. The figure reveals the assumption of constant variance, which is a random scatter plot with the residuals of less than $1.5 \%$. This observation confirms the model accuracy for the influence of the experimental factors

\begin{tabular}{|c|c|c|}
\hline Process Parameters & Log Worth & P-Value \\
\hline MeOH: Oll Mole Ratio (w/w) (6.12) & 6.611 & 0.00000 \\
\hline Temperature $\left({ }^{\circ} \mathrm{C}\right)(55.65)$ & 3.036 & 0.00092 \\
\hline Catalyst Calcination Temperature & 2.795 & 0.00160 \\
\hline Reaction Time (h) (2.4) & 2.341 & 0.00456 \\
\hline Catalyst Quantity $(\%, w / w)(4.8)$ & 0.887 & 0.12981 \\
\hline
\end{tabular}

Figure 4. Pareto Distribution Diagram of the effect of process parameters on \%yield of biodiesel. 
over the \%yield of biodiesel investigated. Fig. 6 shows relationships between the experimental and predicted data, and agrees with the assumption that, when data points split evenly by the 45-degree line, the model is fitted (Dawodu et al., 2014). The figure shows a visual confirmation that the regression model gives a good description of the experimental data with the model. Hence, it can be concluded that the model by the DSD accurately predicted the parameters under study to affect the \%yield of biodiesel.

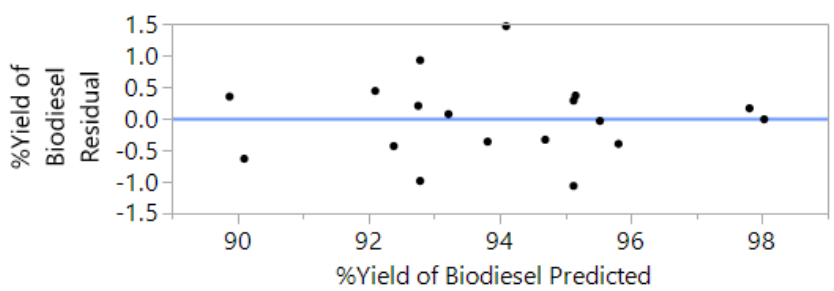

Figure 5. Relationship between Residuals and Predicted Results for \%Yield of Biodiesel.

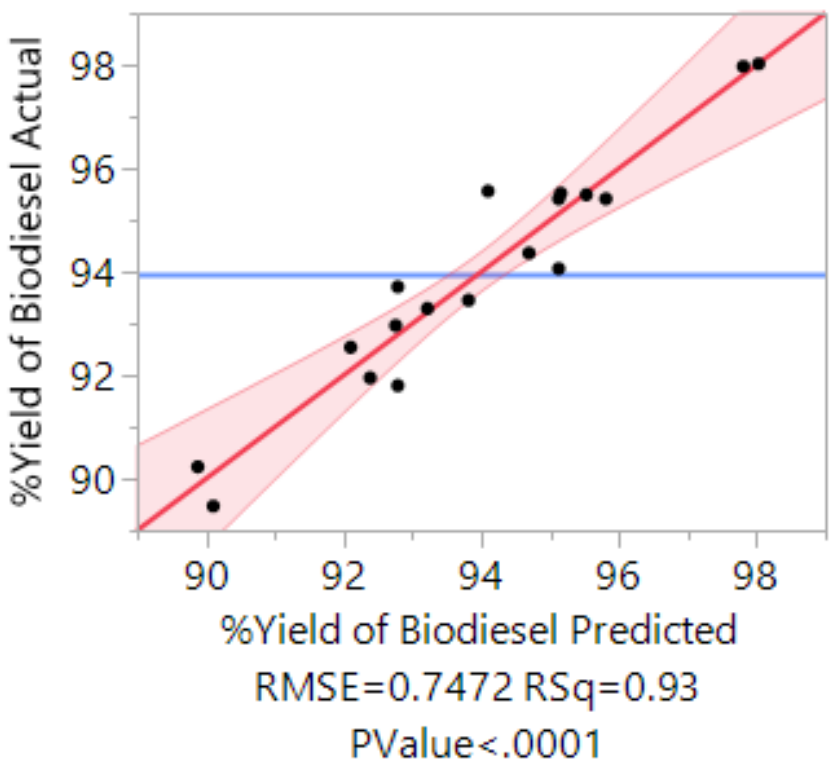

Figure 6. Plot of Experimental versus Predicted Values of $\%$ Yield of PKB.

\section{Effect of the process parameters on the transesterification of PKO to biodiesel Methanol:oil molar ratio}

Fig. 7a shows the effect of methanol/oil molar ratio for both DCC 800 and DCC900 on the \%yield of biodiesel. The figure shows an increase in biodiesel yield steadily to maximum values of 97.2 and $95 \%$ for DCC 800 and DCC 900 at $\mathrm{MeOH}$ :oil mole ratio (w/w) of 12:1. The correlation of MeOH:oil mole ratio (w/w) with other process parameters was studied and shown in Fig. 9(a-f). It revealed that, for both catalysts, the increase in the $\mathrm{MeOH}$ :oil mole ratio (w/w) increases the \%yields of biodiesel. Regardless of its interactions with other parameters, $\mathrm{MeOH}$ : Oil mole ratio (w/w) of 12:1 gave the highest yield of biodiesel. Mootabadi et al. (2010) obtained a similar result of highest yield of biodiesel at $\mathrm{MeOH}$ :oil mole ratio (w/w) of 12:1. This showed that, when the heterogeneous catalyst is used for biodiesel production, the backward reaction might proceed at lower stoichiometric $\mathrm{MeOH}$ :oil mole ratio $(\mathrm{w} / \mathrm{w})$, where the reaction is expected to be forward toward biodiesel production. It is observed that higher $\mathrm{MeOH}$ :oil mole ratio (w/w) is required to obtain the highest yield of biodiesel, as the methanol phase is expected to be in contact with hydrophilic catalyst surface (Korkut and Bayramoglu, 2016).

\section{Temperature}

Fig. $7 \mathrm{~b}$ shows the effect of reaction temperature for both catalysts (DCC 800 and DCC900) on the \%yield of biodiesel. It was observed that a reaction temperature of $60^{\circ} \mathrm{C}$ gave the highest yield of $96 \%$ biodiesel for DCC 800 , whereas a temperature of $65^{\circ} \mathrm{C}$ gave the highest yield of $94.5 \%$ biodiesel for DCC 900 . This highest yield for both catalysts was due to the fact that high temperature improves the catalytic activity of the heterogeneous catalyst and thereby speeds the rate of reaction and increases the biodiesel yields (Korkut and Bayramoglu, 2016; Xue et al., 2014). Fig. 10 depicts the interactions of reaction temperature with other process parameters, which corroborates Fig. $7 \mathrm{~b}$. As the temperatures increased, the \%yield of biodiesel increases regardless of the interaction with other parameters. This shows that the temperature is significant (Table 5) with $p<0.0009$, in the transesterification reaction of PKO for biodiesel production.

The reaction mechanism of heterogeneous catalyst takes place on the surface of the catalyst where adsorption of reactants and desorption of products occur. Catalyst quantity of 4,6 and $8(\%, w / w)$ was investigated to determine the effect on the \%yield of biodiesel as shown in Fig. 7c. Fig. 7c revealed that the $\%$ yield of biodiesel increased as the catalyst quantity increases up to $8 \%(\mathrm{w} / \mathrm{w})$ for DCC 800 . For DCC 900 , $6 \%(\mathrm{w} / \mathrm{w})$ of catalyst resulted in maximum \%yield of biodiesel. The greater the catalyst quantity, the higher the active basic sites in the reaction medium which results in higher conversions to methyl esters (Correia et al., 2014). However, too much catalyst in excess of that required for the reaction can lead to soap formation, hence reducing the \%yield of biodiesel.

The optimization investigation, Figs. 9 ( $a$ and $b$ ), 10 ( $c$ and $d$ ) and 11 ( $a$ and $b)$, revealed that an average catalyst quantity of $8 \%(\mathrm{w} / \mathrm{w})$ gave maximal yields of $97,94.5,96.5,95,95$ and $95 \%$ respectively.

\section{Catalyst Quantity}

Fig. 8 presents the mechanism of the transesterification reaction of vegetable oil (PKO) by a solid catalyst $(\mathrm{CaO})$ as was shown by Marinković et al. (2016). 

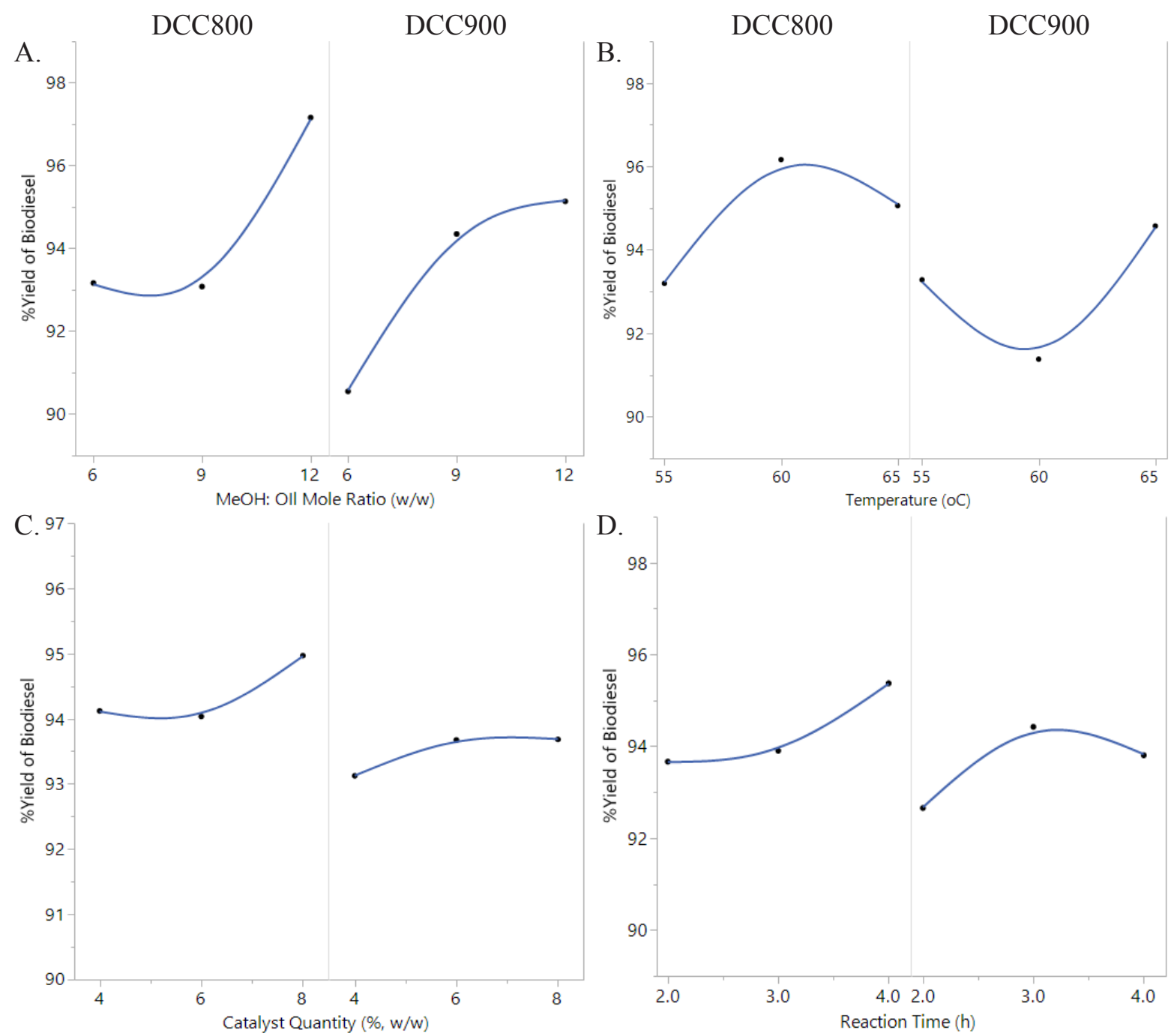

Figure 7. Effect of Process Parameters on the \%Yield of Biodiesel (a) MeOH:oil Mole Ratio (b) Temperature (c) Catalyst Quantity (d) Reaction Time.

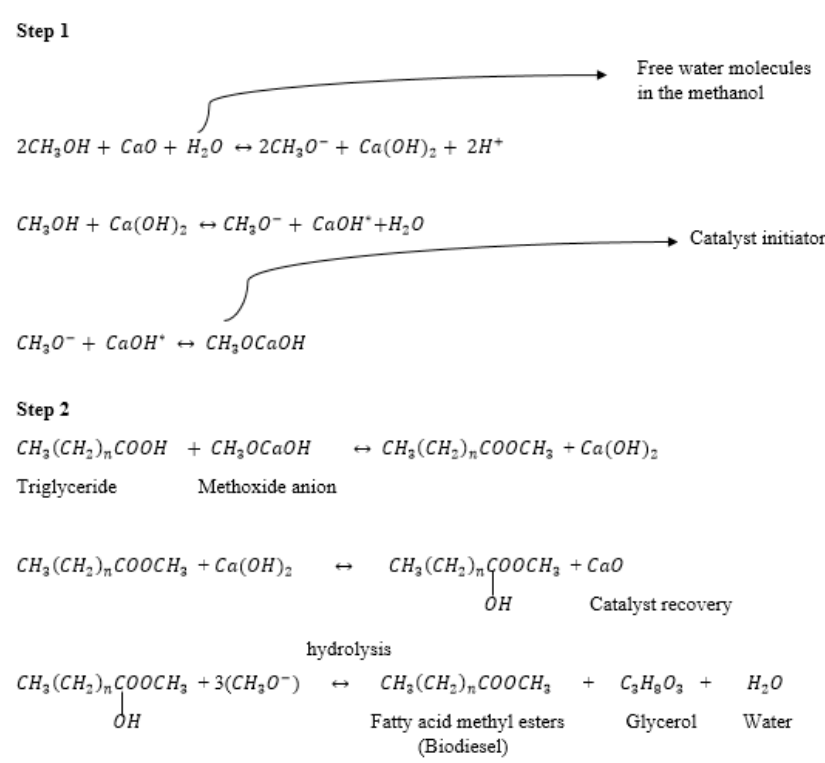

Figure 8. Mechanism of Transesterification Reaction by $\mathrm{CaO}$ for Biodiesel Production, according to (Marinković et al. (2016).
It was seen from the Fig. 8 that the interactions of catalyst quantity with other parameters show an increase in the \%yield of biodiesel as the catalyst quantity increases to $8 \%(\mathrm{w} / \mathrm{w})$.

\section{Reaction time}

Correia et al. (2015) reported that excess reaction time dislocates the equilibrium reaction, thereby leading to the hydrolysis of methyl esters (biodiesel) and decrease in biodiesel conversion. This led to the optimization of the reaction time in this study. Fig. 7d shows DCC800 increases the \%yield of biodiesel from 93.3 to $95.3 \%$, as the reaction time increases from 2 to $4 \mathrm{~h}$. DCC 900 increases the \%yield of biodiesel from 92.3 to $94.2 \%$ when the reaction time was increased from 2 to $3 \mathrm{~h}$ and decreased afterward to $93.5 \%$ when the time was increased to $4 \mathrm{~h}$. This shows that $3 \mathrm{~h}$ was sufficient to achieve the maximum yield of biodiesel for the DCC 900 catalyst. The biodiesel yield obtained in this study is greater than $91.8 \%$ reported by Ilgen (2011) when dolomite catalyst was used for canola oil. 

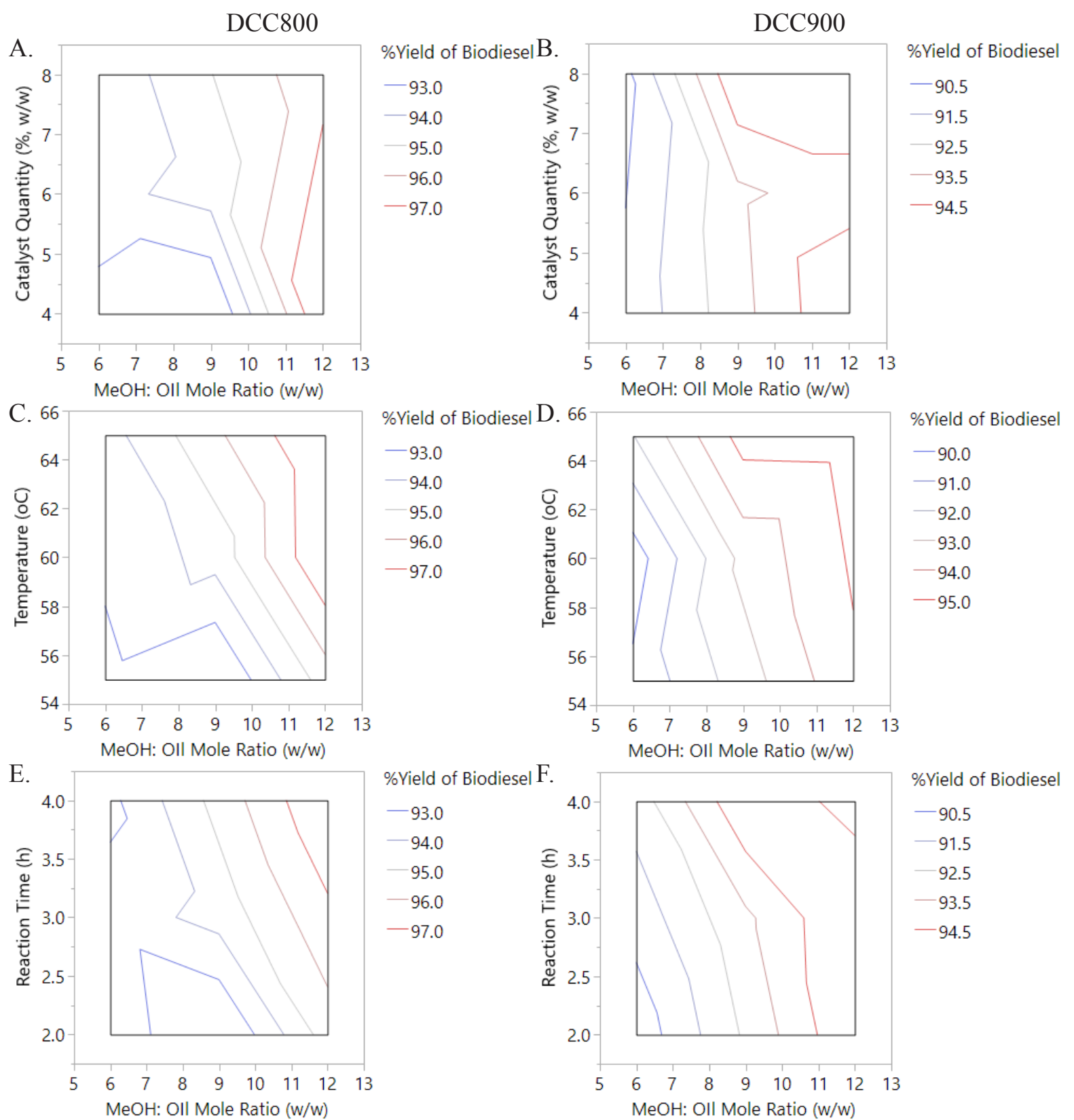

Figure 9. Contour Plot of \%Yield of Biodiesel by Interaction between MeOH: Oil Mole Ratio (w/w) and Other Parameters for DCC800 and DCC900.

The interactions of reaction time with other parameters (Figs. 9(e and f), 10(a and b) and 11(a and b)) depicted that the optimum reaction time of $4 \mathrm{~h}$ yielded the highest biodiesel when PKO was used in the presence of dolomite catalyst.

\section{Calcination temperature}

It was observed that the DCC800 gave an improved yield of $97 \%$ biodiesel compared to DCC900 that yielded 95\% biodiesel as shown in Figs 7, 9 and 10. This may be that the DCC 800 was obtained as the more active catalyst than DCC900. The calcination temperature of $800^{\circ} \mathrm{C}$ for DCC 800 might have led to the desorption of carbon dioxide. This forms basic sites that catalyzed transesterification of vegetable oil with methanol to give higher biodiesel yield. However, the lower biodiesel yield of DCC900 may be due to the effect of higher calcination temperature, which can cause atoms in the small particles of the catalyst to diffuse to the boundary and lump together to form a larger particle. This can result in a severe reduction of the unit cells of the catalyst after the complete de-carbonation (Jazie et al., 2013b). The higher calcination temperature of $900^{\circ} \mathrm{C}$ might also have reduced the base strength and the activity of DCC900 catalyst, thereby reducing the \%yield of PKB (Wibowo et al., 2011). It is a known fact that the decrease of the specific surface area of a catalyst is unfavorable for a higher yield of biodiesel. However, 

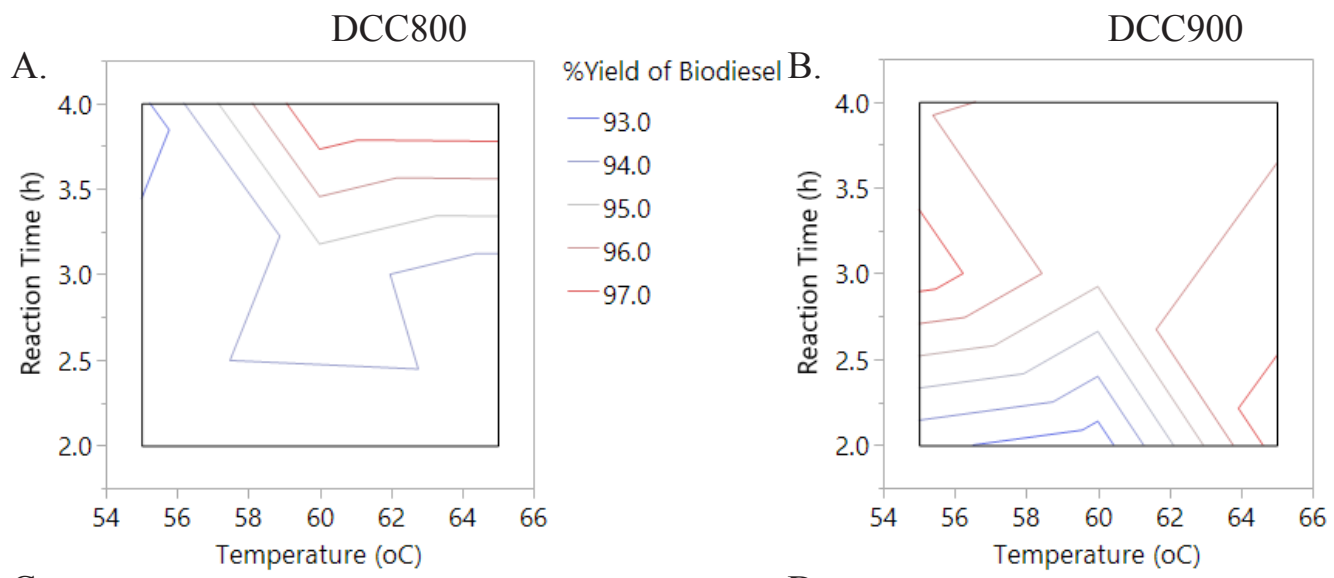

$\%$ Yield of Biodiesel
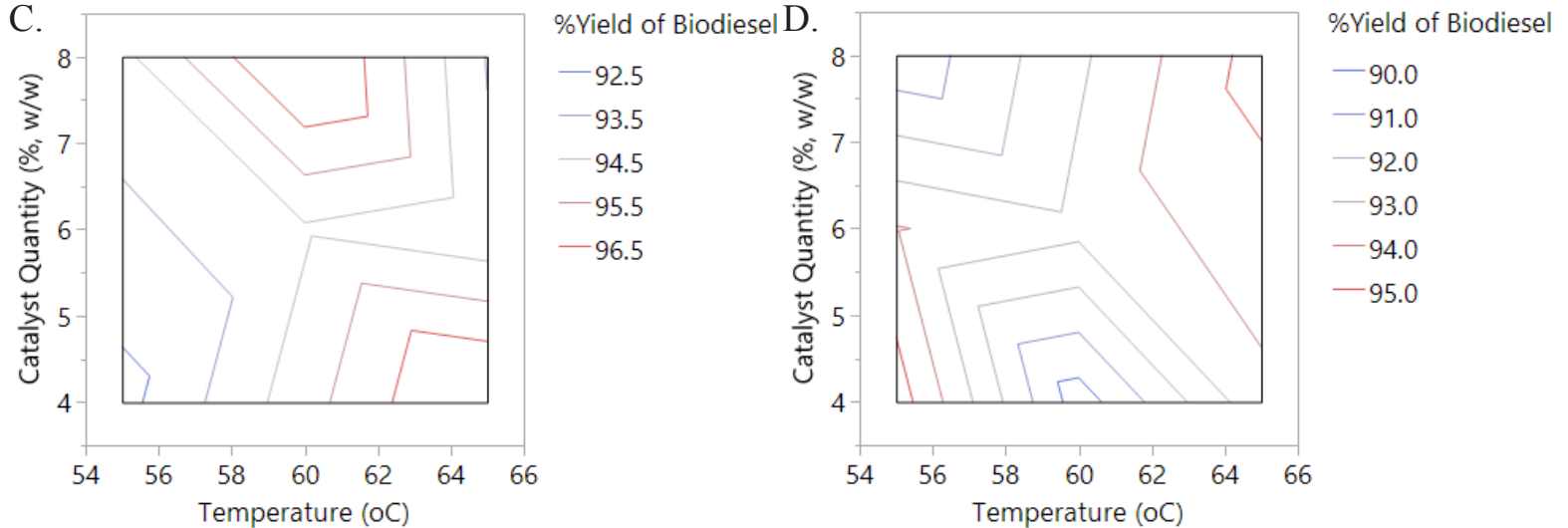

Figure 10. Contour Plot for \%Yield of Biodiesel by Interaction between Temperature $\left({ }^{\circ} \mathrm{C}\right)$ and Other Parameters.
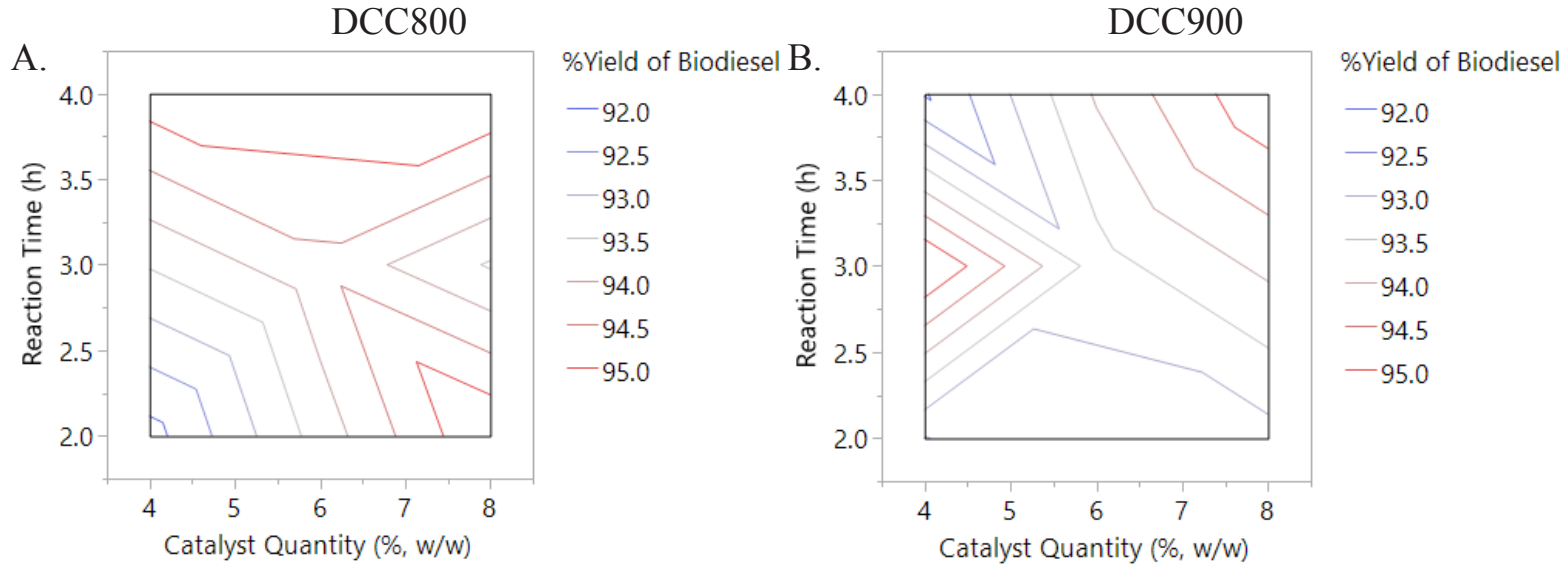

Figure 11. Contour Plot for \%Yield of Biodiesel by Interaction between Catalyst Quantity (w/w) and Reaction Time (h).

in this case, the DCC 800 was the most active catalyst, which is likely related to the changes of the basic sites and strength on the surfaces of the catalysts due to the effect of temperature (Fujie et al., 2015 ).

\section{Optimization and model validation of the process parameters}

The process parameters for the dolomitic catalytic transesterification of $\mathrm{PKO}$ were $\mathrm{MeOH}$ :oil molar ratio, reaction temperature, catalyst quantity, reaction time and catalyst calcined temperature with optimal values of $12: 1$ $(\%, \mathrm{w} / \mathrm{w}), 65^{\circ} \mathrm{C}, 8 \%(\mathrm{w} / \mathrm{w}), 4 \mathrm{~h}$ and $800^{\circ} \mathrm{C}$, respectively as shown in Table 7. The accuracy of the model was validated by carrying out the transesterification reaction of the PKO using the optimal process parameters. The result obtained was $98.92 \%$ yield of PKB as compared with the predicted value of $98.69 \%$ from the model. The error between the experimental and predicted results was $0.23 \%$. This showed that the model is valid and confirmed the validity of the predicted model.

\section{Reusability of dolomitic catalyst}

One of the major benefits of a solid catalyst, when compared with homogeneous catalysts from 
Table 7. Optimal Conditions for the \%Yield of PKB.

\begin{tabular}{|c|c|c|c|c|c|c|c|c|}
\hline $\begin{array}{c}\text { Process Conditions } \\
\text { (Coded) }\end{array}$ & $\mathbf{X}_{1}$ & $\mathbf{X}_{2}$ & $\mathbf{X}_{3}$ & $\mathbf{X}_{4}$ & $\mathrm{X}_{5}$ & $\begin{array}{l}\text { Predicted } \\
\% \text { PKB } \\
\end{array}$ & $\begin{array}{l}\text { Actual } \\
\text { \%PKB }\end{array}$ & \%Error \\
\hline Optimal Values & 12 & 65 & 8 & 4 & 800 & 98.69 & 98.92 & 0.23 \\
\hline
\end{tabular}

technical, environmental and economic points of view, is its reusability. In this study, the reusability of the dolomitic catalyst was investigated by first recovering it through filtration at the end of every reaction and reusing it for biodiesel production from PKO for nine experimental runs. Fig. 12 presents the result obtained and indicated that the dolomitic catalyst can be reused 8 times in transesterification of PKO for biodiesel production with a $<4 \%$ biodiesel yield loss. This is similar to the finding of Korkut and Bayramoglu (2016). The yield obtained as shown in the figure was $94.99 \%$ after the 8 th cycle of transesterification. This showed that the catalyst could be re-used for 8 cycles without losing its activity. At the $9^{\text {th }}$ cycle, the yield decreased to $89.76 \%$ from $98.92 \%$ at the first run, which might have been due to partial deactivation and structural changes in the catalyst, as the presence of water in the reaction causes structural changes in the catalyst (Jazie et al., 2013b). Leaching of the active sites by the reaction mixture might have caused the catalyst deactivation, thereby reducing the calcium quantity in the catalyst (Buasri et al., 2013; Santos et al., 2014). Therefore, the reduced activity of the catalyst at the $9^{\text {th }}$ cycle indicates that it is highly stable and reusable. These important characteristics in the Nigerian dolomitic catalyst show it is a good heterogeneous catalyst.

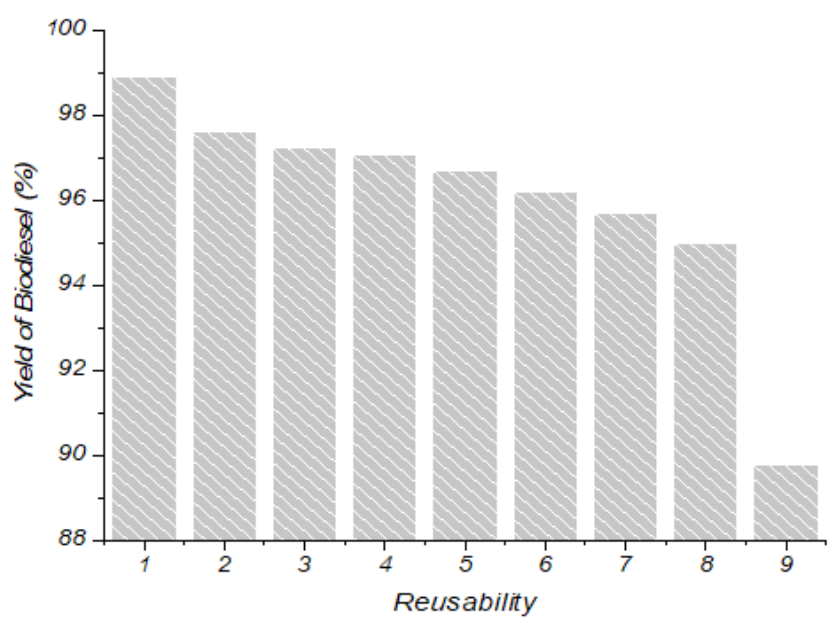

Figure 12. Reusability of Dolomitic Catalyst for $\%$ Yield of Biodiesel.

\section{Physicochemical properties and FAMEs profile of the PKB from the dolomitic catalyst}

The physicochemical properties obtained for the PKB are methyl ester content $99.06 \%$, density 0.868 $\mathrm{g} / \mathrm{cm}^{3}$, kinematic viscosity $2.80 \mathrm{~mm}^{2} / \mathrm{s}$, flash point $138.5^{\circ} \mathrm{C}$, cloud point $9^{\circ} \mathrm{C}$, pour point $4^{\circ} \mathrm{C}$, water content $<0.005$, and sulfur content $<0.005$ as shown in Table 8 . The table also includes results of the aforementioned properties for the PKO and ASTM standard for biodiesel (ASTM D6751). The results show that the biodiesel obtained with the dolomitic catalyst is of good quality, as all the measured properties fall within the range of the standard. This showed that the catalyst demonstrated great catalytic performance for biodiesel production.

Fig. 13 is the GCMS spectra of the PKB with nine major peaks; each of the peaks corresponds to a FAME that was identified by the NIST library (NIST 11). The FAMEs observed as shown in Table 9 were methyl decanoate, methyl caprate, methyl laurate, methyl myristate, methyl palmitate, methyl stearate, methyl oleate and others with percentage composition of $0.91,0.79,25.97,13.02,13.39$, $1.79,36.42$ and 6.77 , respectively. These gave a total FAMEs percentage composition of $99.06 \%$, which is above $96.5 \%$ recommended by the ASTM. The retention time and molecular formula as obtained are also shown in the table. From the percentage composition, $36.42 \%$ of the FAME were unsaturated while $62.64 \%$ were saturated fatty acids. This shows the quality of biodiesel from PKO using the dolomitic catalyst, consisting of higher percentage composition of saturated fatty acid, indicating more oxidative and thermal stability of the biodiesel. The high oxidative stability of the biodiesel is responsible for low deterioration rate and improved shelf life, particularly in high-temperature environments (Cherng-Yuan and Yi-Wei, 2012). The presence of unsaturated fatty acids in an appropriate quantity in biodiesel is an additional advantage as it is responsible for density, viscosity, lower cetane number and heating value, emits lower $\mathrm{HC}, \mathrm{CO}$ and Smoke emissions, maximum gas pressure and exhaust gas temperature. But when unsaturated fatty acids are more than enough in any biodiesel, it emits more nitrogen oxides (Gopinath et al., 2010). However, the results of the physicochemical properties of biodiesel have a strong relationship with their FAMEs profile (Shahabuddin et al., 2013). Hence, the presence of saturated fatty acids and unsaturated fatty acids in the biodiesel confirmed its quality as all the physicochemical properties determined fall within the ASTM standard as shown in Table 8. 


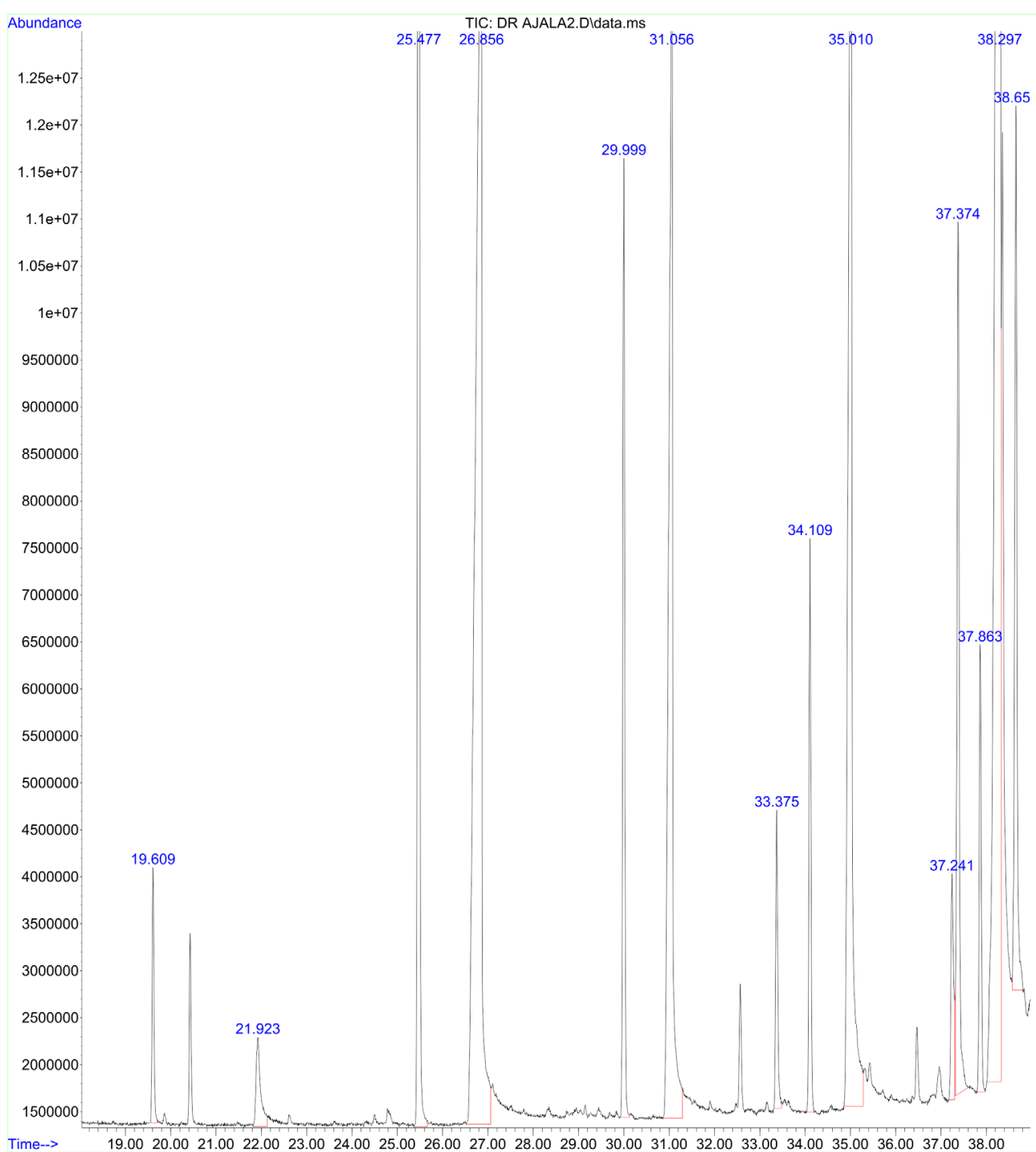

Figure 13. Fatty Acid Methyl Esters Composition of PKB Synthesized by the Dolomitic Catalyst.

Table 8. Fuel Properties of PKB and Biodiesel Standard.

\begin{tabular}{|c|c|c|c|}
\hline Fuel properties (units) & PKB & PKO & Standard for biodiesel (ASTM D6751) \\
\hline FAME content $(\%)$ & 99.06 & - & $\geq 96.5$ \\
\hline Density@15이 $\left.\mathrm{C} / \mathrm{cm}^{3}\right)$ & 0.868 & 0.922 & $0.8 \overline{60}-0.900$ \\
\hline Kinematic viscosity@ $40^{\circ} \mathrm{C}\left(\mathrm{mm}^{2} / \mathrm{s}\right)$ & 2.80 & 16.29 & $1.9-6.0$ \\
\hline Flash point $\left({ }^{\circ} \mathrm{C}\right)$ & 138.5 & 186 & $\geq 130$ \\
\hline Cloud point $\left({ }^{\circ} \mathrm{C}\right)$ & 9 & 16.5 & $-\overline{3}-12$ \\
\hline Pour point $\left({ }^{\circ} \mathrm{C}\right)$ & 4 & 11.2 & $-15-10$ \\
\hline Water content $(\% \mathrm{w} / \mathrm{w}$ oil $)$ & $<0.005$ & $<0.005$ & $\leq 0.05$ \\
\hline Sulfur content $(\% \mathrm{w} / \mathrm{w}$ oil $)$ & $<0.005$ & $<0.005$ & $\leq 0.005$ \\
\hline
\end{tabular}

Table 9. FAME Profile and Quantitative Analysis of PKB.

\begin{tabular}{ccccc}
\hline $\begin{array}{c}\text { Peak } \\
\text { no. }\end{array}$ & $\begin{array}{c}\text { Retention time } \\
(\text { min) }\end{array}$ & FAMEs present & Molecular formula & \% composition \\
\hline 1 & 19.61 & Methyl decanoate & $\mathrm{C}_{11} \mathrm{H}_{22} \mathrm{O}$ & $\mathrm{C}_{10} \mathrm{H}_{20} \mathrm{O}_{2}$ \\
2 & 21.92 & Methyl caprate & $\mathrm{C}_{13} \mathrm{H}_{26} \mathrm{O}_{2}$ & 0.91 \\
3 & 26.86 & Methyl laurate & $\mathrm{C}_{15} \mathrm{H}_{30} \mathrm{O}_{2}$ & 25.97 \\
4 & 31.06 & Methyl myristate & $\mathrm{C}_{17} \mathrm{H}_{34} \mathrm{O}_{2}$ & 13.02 \\
5 & 35.01 & Methyl palmitate & $\mathrm{C}_{19} \mathrm{H}_{38} \mathrm{O}_{2}$ & 13.39 \\
6 & 37.86 & Methyl stearate & $\mathrm{C}_{19} \mathrm{H}_{36} \mathrm{O}_{2}$ & 1.79 \\
7 & 38.29 & Methyl oleate & - & $36.42 *$ \\
8 & - & Others & 6.77 \\
\hline
\end{tabular}

*The unsaturated fatty acid methyl ester 


\section{CONCLUSION}

The Nigerian dolomite was found to contain essential compounds suitable as a catalyst for biodiesel production. Morphologically, the catalyst possessed a good structure with high pore volume, high surface area, and micropores. Optimization of the process parameters by DSD showed suitable operating conditions for the dolomitic catalyst with $\mathrm{MeOH}$ :oil mole ratio $(12: 1, \mathrm{w} / \mathrm{w})$, temperature $\left(65^{\circ} \mathrm{C}\right)$, catalyst quantity $(8 \%, \mathrm{w} / \mathrm{w})$, reaction time $(4 \mathrm{~h})$ and DCT $\left(800^{\circ} \mathrm{C}\right)$ with the optimum yield of $98.92 \%$ biodiesel. The MeOH: oil mole ratio is the most influential, followed by the reaction temperature that affects \%yield of PKB with $\log$ worth of 6.611 and 3.036 and the F-value of 107.240 and 19.050 , respectively. The reusability of the catalyst studied using the optimal parameters confirmed that the catalyst can be effectively reused for eight runs with a minimal decrease of $<4 \%$ in the biodiesel yield. The quality of the PKB produced by the dolomitic catalyst was confirmed through the physicochemical properties and FAME profile.

Therefore, the Nigerian dolomite is an effective raw material for the synthesis of solid catalyst for biodiesel production, potentially reducing the cost of biodiesel and meeting the increasing global demand for energy.

\section{REFERENCES}

Aladetuyi, A., Olatunji, G. A., Ogunniyi, D. S., Odetoye, T. E., Oguntoye, S. O. Production and characterization of biodiesel using palm kernel oil; fresh and recovered from spent bleaching earth. Biofuel Research Journal, 4, 134-138 (2014). https://doi.org/10.18331/BRJ2015.1.4.6

Alamu, O. J., Akintola, T. A., Enweremadu, C. C., Adeleke, A. E. Characterization of palm kernel oil biodiesel produced through $\mathrm{NaOH}$-catalysed transesterification process. Scientific Research and Essay, 3, 308-311 (2008).

Almerindoa, G. I., Probsta, L. F. D., Campos, C. E. M., Almeidac, R. M. de, Meneghettic, S. M. P., Meneghettic, M. R., Clacensd, J.-M., Fajardoe, H. V. Magnesium oxide prepared via metal-chitosan complexation method: Application as catalyst for transesterification of soybean oil and catalyst deactivation studies. Journal of Power Sources, 196, 8057-8063 (2011). https://doi.org/10.1016/j. jpowsour.2011.05.030

Buasri, A., Chaiyut, N., Loryuenyong, V., Wongweang, C., Khamsrisuk, S. Application of Eggshell Wastes as a Heterogeneous Catalyst for Biodiesel Production. Sustainable Energy, 1, 7-13 (2013).

Cherng-Yuan, L., Yi-Wei, L. Fuel characteristics of biodiesel produced from a high-acid oil from soybean soapstock by supercritical-methanol transesterification. Energies, 5, 2370-2380 (2012). https://doi.org/10.3390/en5072370

Correia, L. M., Campelo, N. da S., Novaes, D. S., Cavalcante Jr., C. L., Cecilia, J. A., RodríguezCastellón, E., Vieira, R. S. Characterization and application of dolomite as catalytic precursor for canola and sunflower oils for biodiesel production. Chemical Engineering Journal, 269, 35-43 (2015). https://doi.org/10.1016/j.cej.2015.01.097

Correia, L. M., Saboya, R. M. A., Campelo, N., Cecilia, J. A., Rodríguez-Castellón, E., Cavalcante Jr., C. L., Vieira, R. S. Characterization of calcium oxide catalysts from natural sources and their application in the transesterification of sunflower oil. Bioresource Technology, 151, 207-213 (2014). https://doi.org/10.1016/j.biortech.2013.10.046

Dawodu, F. A., Ayodele, O. O., Bolanle-Ojo, T., Biodiesel production from Sesamum indicum $\mathrm{L}$. seed oil: An optimization study. Egyptian Journal of Petroleum, 23, 191-199 (2014). https://doi. org/10.1016/j.ejpe.2014.05.006

Dhawane, S. H., Kumar, T., Halder, G. Parametric effects and optimization on synthesis of iron (II) doped carbonaceous catalyst for the production of biodiesel. Energy Conversion and Management, 122, 310-320 (2016). https://doi.org/10.1016/j. enconman.2016.06.005

Donnelly, T. Creating and analyzing definitive screening designs. In S. I. Inc (Ed.), JMP, A Business Unit of SAS: 1-52. SAS Campus Drive Cary, NC 27513: SAS Institute Inc ${ }^{\wedge}(2016)$.

Ezeoha, S. L., Akubuo, C. O., Ani, A. O. Indigenous design and manufacture of palm kernel oil screw press in Nigeria: Problems and prospects. International Journal of Applied Agricultural Research, 2, 67-82 (2012).

Ferdous, K., Uddin, M. R., Uddin, M. R., Khan, M. R., Islam, M. A. Preparation and optimization of biodiesel production from mixed feedstock oil. Chemical Engineering and Science, 1, 62-66 (2013). https://doi.org/10.12691/ces-1-4-3

Fujie, L., Wei, Y., Xinhai, Y., Shan-Tung, T. Transesterification of vegetable oil to biodiesel over $\mathrm{MgO}-\mathrm{Li}_{2} \mathrm{O}$ catalysts templated by a PDMSPEO comb-like copolymer. Energy Procedia, 75, 72-77 (2015 ). https://doi.org/10.1016/j. egypro.2015.07.140

Gopinath, A., Puhan, S., Nagarajan, G. Effect of unsaturated fatty acid esters of biodiesel fuels on combustion, performance and emission characteristics of a DI diesel engine. International Journal of Energy and Environmental Engineering, 1, 411-430 (2010).

Gorji, A. Animal renewable waste resource as catalyst in biodiesel production. Journal of Biodiversity and Environmental Sciences, 7, 36-49 (2015). 
Gupta, J., Agarwal, M., Dalai, A. K. Optimization of biodiesel production from mixture of edible and nonedible vegetable oils. Biocatalysis and Agricultural Biotechnology, 8, 112-120 (2016). https://doi.org/10.1016/j.bcab.2016.08.014

Hariharan, M., Varghese, N., Cherian, A. B., Sreenivasan, P. V., Paul, J., Antony, K. A. Synthesis and characterisation of $\mathrm{CaCO}_{3}$ (calcite) nano particles from cockle shells using chitosan as precursor. International Journal of Scientific and Research Publications, 4, 1-5 (2014).

Ilgen, O. Dolomite as a heterogeneous catalyst for transesterification of canola oil. Fuel Process Technology, 92, 452-455 (2011). https://doi. org/10.1016/j.fuproc.2010.10.009

Jazie, A. A., Pramanik, H., Sinha, A. S. K. Transesterification of peanut and rapeseed oils using waste of animal bone as cost effective catalyst. Material Renewable and Sustainable Energy, 2, 1-10 (2013a). https://doi.org/10.1007/ s40243-013-0011-4

Jazie, A. A., Pramanik, H., Sinha, A. S. K., Jazie, A. A. Egg shell as eco-friendly catalyst for transesterification of rapeseed oil: Optimization for biodiesel production. International Journal of Sustainable Development and Green Economics, 2, 27-32 (2013b). https://doi.org/10.1007/s40243013-0011-4

Ji, J., Ge, Y., Balsam, W., Damuth, J. E., Chen, J. Rapid identification of dolomite using a Fourier Transform Infrared Spectrophotometer (FTIR): A fast method for identifying Heinrich events in IODP Site U1308. Marine Geology, 258, 60-68 (2009). https://doi.org/10.1016/j.margeo.2008.11.007

Jindapon, W., Jaiyen, S., Ngamcharussrivichai, C. Seashell-derived mixed compounds of $\mathrm{Ca}$, $\mathrm{Zn}$ and $\mathrm{Al}$ as active and stable catalysts for the transesterification of palm oil with methanol to biodiesel. Energy Conversion and Management, 122, 535-543 (2016). https://doi.org/10.1016/j. enconman.2016.06.012

Jones, B., Nachtsheim, C. J. Definitive screening designs with added two-level categorical factors. Journal of Quality Technology, 45, 121-129 (2013). https://doi.org/10.1080/00224065.2013.11917921

Korkut, I., Bayramoglu, M. Ultrasound assisted biodiesel production in presence of dolomite catalyst. Fuel, 180, 624-629 (2016). https://doi. org/10.1016/j.fuel.2016.04.101

Lee, H. V., Juan, J. C., Abdullah, N. F. B., Rabiah, N. M. F., Taufiq-Yap, Y. H. Heterogeneous base catalysts for edible palm and non-edible Jatropha-based biodiesel production. Chemistry Central Journal, 8, 1-9 (2014). https://doi.org/10.1186/1752$153 \mathrm{X}-8-30$
Marcel, P. Design of Experiments Guide. In S. I. Inc (Ed.), JMP, A Business Unit of SAS, 12 ed.: 1-618. SAS Campus Drive Cary, NC 27513: SAS Institute Inc (2015).

Margaretha, Y. Y., Prastyo, H. S., Ayucitra, A., Ismadji, S. Calcium oxide from Pomacea sp. shell as a catalyst for biodiesel production. International Journal of Energy and Environmental Engineering, 3, 1-9 (2012). https://doi.org/10.1186/2251-68323-33

Marinković, D. M., Stanković, M. V., Veličković, A. V., Avramović, J. M., Miladinović, M. R., Stamenković, O. O., Veljković, V. B., Jovanović, D. M. Calcium oxide as a promising heterogeneous catalyst for biodiesel production: Current state and perspectives. Renewable and Sustainable Energy Reviews, 56, 1387-1408 (2016). https://doi. org/10.1016/j.rser.2015.12.007

Mohan, S. K. Studies on optimization of biodiesel production-snail shell as eco-friendly catalyst by transesterification of neem oil. International Journal of Innovative Research in Technology, Science \& Engineering, 1, 5-10 (2015).

Monteiro, M. R., Ambrozin, A. R. P., Liao, L. M., Ferreira, A. G. Determination of biodiesel blend levels in different diesel samples by ${ }^{1} \mathrm{H}$ NMR,. Fuel, 88, 691-696 (2009). https://doi.org/10.1016/j. fuel.2008.10.010

Mootabadi, H., Salamatinia, B., Bhatia, S., Abdullah, A. Z. Ultrasonic-assisted biodiesel production process from palm oil using alkaline earth metal oxides as the heterogeneous catalysts. Fuel, 89, 1818-1825 (2010). https://doi.org/10.1016/j. fuel.2009.12.023

Muthu, K., Viruthagiri, T. Application of solid base calcium oxide as a heterogeneous catalyst for the production of biodiesel. International Journal of ChemTech Research, 8, 2002-2008 (2015).

Ngamcharussrivichai, C., Wiwatnimit, W., Wangnoi, S. Modified dolomites as catalysts for palm kernel oil transesterification. Journal of Molecular Catalysis A: Chemical, 276, 24-33 (2007). https:// doi.org/10.1016/j.molcata.2007.06.015

Niu, S.-L., Huo, M.-J., Lu, C.-M., Liu, M.-Q., Li, $\mathrm{H}$. An investigation on the catalytic capacity of dolomite in transesterification and the calculation of kinetic parameters. Bioresource Technology, 158, 74-80 (2014). https://doi.org/10.1016/j. biortech.2014.01.123

Roschat, W., Siritanon, T., Yoosuk, B., Promarak, V. Rice husk-derived sodium silicate as a highly efficient and low-cost basic heterogeneous catalyst for biodiesel production. Energy Conversion and Management, 119, 453-462 (2016). https://doi. org/10.1016/j.enconman.2016.04.071 
Santos, R. C. R., Vieira, R. B., Valentini, A. Optimization study in biodiesel production via response surface methodology using dolomite as a heterogeneous catalyst. Journal of Catalysts, 2014, 1-11 (2014). https://doi. org $/ 10.1155 / 2014 / 213607$

Shahabuddin, M., Liaquat, A. M., Masjuki, H. H., Kalam, M. A., Mofijur, M. Ignition delay, combustion and emission characteristics of diesel engine fueled with biodiesel. Renewable and Sustainable Energy Reviews, 21, 623-632 (2013). https://doi.org/10.1016/j.rser.2013.01.019

Shajaratun Nur, Z. A., Taufiq-Yap, Y. H., Rabiah Nizah, M. F., Teo, S. H., Syazwani, O. N., Islam, A. Production of biodiesel from palm oil using modified Malaysian natural dolomites. Energy Conversion and Management, 78, 738-744(2014). https://doi.org/10.1016/j.enconman.2013.11.012

Singh, A., He, B., Thompson, J., Gerpen, J. V. Process optimization of biodiesel production using alkaline catalysts. Applied Engineering in Agriculture, 22, 597-600 (2006). https://doi. org/10.13031/2013.21213

Sulaiman, S., Shah, B., Jamal, P. Production of biodiesel from palm oil using chemically treated fish bone catalyst. Chemical Engineering Transactions, 56, 1525-1530 (2017).

Wibowo, T. Y., Abdullah, A. Z., Zakaria, R. Effect of calcination temperature and Tmaoh on catalytic activity of basic clay. Journal of Applied Sciences, 11, 3619-3624 (2011). https://doi.org/10.3923/ jas.2011.3619.3624

Xuan, W., Leung, D. Y. C. Orthogonal array design for biodiesel production optimization - using ultrasonic-assisted transesterification of Camelina sativa L. Crantz oil, World Renewable Energy Congress, Vol. 79: 79-86. Linkoping, Sweden: Bioenergy Technology (2011).

Xue, B., Luo, J., Zhang, F., Fang, Z. Biodiesel production from soybean and Jatropha oils by magnetic $\mathrm{CaFe}_{2} \mathrm{O}_{4}$ $\mathrm{Ca}_{2} \mathrm{Fe}_{2} \mathrm{O}_{5}$-based catalyst. Energy, 68, 584-591 (2014). https://doi.org/10.1016/j.energy.2014.02.082 